\title{
Entrevista: A literatura segundo Luiz Ruffato
}

\author{
Janine Resende Rocha \\ Universidade Federal de Minas Gerais
}

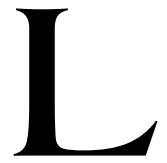

uiz Ruffato nasceu em 1961, em Cataguases, cidade mineira onde se passa parte de suas histórias. Formado em Comunicação Social pela Universidade Federal de Juiz de Fora (UFJF), atualmente radicado em São Paulo, dedica-se exclusivamente à literatura.

O autor publicou Histórias de Remorsos e Rancores (histórias, 1998); (os sobreviventes) (histórias, 2000); Eles eram muitos cavalos (romance, 2001); As máscaras singulares (poemas, 2002); Os ases de Cataguases: uma história dos primórdios do Modernismo (ensaio, 2002); Mamma, son tanto felice (Inferno Provisório - volume I, romance, 2005); O mundo inimigo (Inferno Provisório - volume II, romance, 2005) e Vista parcial da noite (Inferno Provisório - volume III, romance, 2006). Editou os livros Fora da Ordem e do Progresso (2004) - organizado junto com Simone Ruffato; 25 mulheres que estão fazendo a nova literatura brasileira (2004); Ascânio Lopes, todos os possiveis caminhos (2005); Mais 30 mulheres que estão fazendo a nova literatura brasileira (2005); Quando fui outro (2006) e Entre nós (2007). Participa também de diversas publicações coletivas.

O romance Eles eram muitos cavalos foi publicado na Itália (Milano, Bevivino Editore, 2003), na França (Paris, Éditions Métailié, 2005) e em Portugal (Espinho, Quadrante, 2006). Com esse livro, o autor ganhou os Prêmios Machado de Assis de Narrativa, da Fundação Biblioteca Nacional, e APCA (Associação Paulista de Críticos de Arte), prêmio recebido também em 2005, com Mamma, son tanto felice - publicado na França (Paris, Éditions Métailié, 2007) - e O mundo inimigo. (os sobreviventes) recebeu menção especial no Prêmio Casa de las Américas, de Cuba.

Nesta entrevista, concedida em maio de 2007, Luiz Ruffato fala sobre a sua visão da literatura, evidenciando as bases do seu projeto literário, propostas junto ao potencial político e subversivo admitido por ela. 
1. Você já foi pipoqueiro, caixa de bar, balconista, operário têxtil, torneiro-mecânico, jornalista, sócio de empresa de assessoria de imprensa, gerente de lanchonete, vendedor de livros. Como a literatura torna-se uma escolha profissional?

LR: Eu percebo o ofício literário como uma escolha entre várias. Eu não nasci predestinado a ser escritor - ninguém nasce. A minha opção se deu em função de questionamentos políticos. Minha mãe era filha de pequenos proprietários rurais em Rodeiro, uma colônia italiana desenraizada e paupérrima, que vivia da cultura de subsistência, próxima a Ubá. Analfabeta, quando se casou com meu pai, um órfão agregado a uma família italiana em Dona Eusébia, eles não tinham alternativa a não ser migrar. Buscando uma vida melhor (não para eles, mas para seus filhos), chegaram em Cataguases, um núcleo urbano e industrial que oferecia uma infra-estrutura diferenciada das outras cidades da região da Zona da Mata. Foi aí que eu, minha irmã e meu irmão crescemos e estudamos, às custas das trouxas de roupa que minha mãe lavava e do dinheiro que meu pai fazia vendendo pipoca. Meu irmão, formado ajustador-mecânico no Senai, morou em Diadema (na Grande São Paulo) e, de volta a Cataguases, chegou a ocupar um posto importante numa das fábricas de tecido da cidade, a Manufatora. Mas, infelizmente, morreu prematuramente, em 1978, aos 26 anos de idade. Minha irmã trabalhou como tecelã na mesma empresa e, ao se casar - como todas as suas colegas, na época -, virou dona-de-casa (hoje é merendeira de uma escola municipal). Eu, desde os seis anos de idade, acompanhava meu pai, e, para ajudar no orçamento doméstico, exerci as profissões de pipoqueiro, caixeiro de botequim, balconista de armarinho, operário têxtil, até entrar no Senai e me formar em tornearia-mecânica. Em 1978, fui para Juiz de Fora em busca de trabalho (já não se ia tanto, nessa época, para o ABC paulista, pois novas frentes se abriam para a mão-de-obra especializada, na Fiat, em Contagem, e nas siderúrgicas do Vale do Aço mineiro). Lá descobri a Universidade Federal de Juiz de Fora, onde estudei jornalismo, e, concomitantemente, percebi a minha ignorância. Envolvi-me com a política estudantil e com a literatura. E surpreendi-me com o fato de que não há praticamente nenhum registro da classe operária urbana nos romances e contos brasileiros. Então decidi que, se algum dia eu fosse escrever algo, queria dar um depoimento da minha época, por meio da minha vivência. O escritor, para mim, é apenas isto: um repositório da memória coletiva. Foi assim que escolhi tornar-me um escritor profissional. 
2. A sua presença constante na cena editorial-seja como organizador, seja como escritor de livros individuais ou de contos integrantes de publicações temáticas como Contos de agora (2007), Os donos da bola (2006), Tarja Preta (2005), só para citar as mais recentes - e em feiras e fóruns literários indica que você trabalha bastante. Como é viver de literatura num país como o Brasil?

LR: É difícil, pois falta profissionalismo de ambos os lados, das editoras e dos escritores. Eu não me queixo das editoras com as quais trabalho todas têm sido extremamente corretas no cumprimento dos contratos. Agora, essa não é a tônica do mercado. Creio, no entanto, que a responsabilidade por esse problema deve recair mais sobre os meus colegas que encaram a literatura como diletantismo - e, portanto, com amadorismo. Escrever um livro, ou uma orelha, ou um prefácio, ou uma resenha, ou proferir uma palestra ainda encontra-se no domínio da vaidade pessoal. Então, cria-se toda uma estrutura amadora para retroalimentar isso. Os autores pagam para publicar seus livros - ou não recebem os direitos autorais -, as editoras não remuneram pelas orelhas e prefácios, os jornais não gratificam pelas resenhas, as instituições não recompensam pelas palestras... O escritor ainda vê no editor um bom samaritano e o editor vê no autor um coitado, a quem fará um enorme favor publicando seu trabalho. Eu tenho tentado, na medida do possível, resistir a isso. Não escrevo resenhas ou orelhas ou prefácios de graça; recebo direitos autorais adiantados (a maior parte das vezes equivalentes à primeira edição) e cobro por palestras (nem que sejam valores simbólicos). Entretanto, luto contra a corrente...

3. As suas histórias estão calcadas sobre a realidade sócio-econômica brasileira. A aferição realista não implica, contudo, o descuido dos parâmetros estéticos. Há, assim, uma atenção ao ritmo, à linguagem, às imagens e um experimentalismo formal marcante. Como se dá o seu processo de criação e qual o seu método de escrita?

LR: Como escritor profissional, escrevo todos os dias. É o meu ofício. Há uma glamourização da figura do artista, ingenuamente alimentada pelos próprios, que serve exclusivamente aos interesses do poder. $\mathrm{Na}$ medida em que apontam os escritores como "loucos", "malucos", "doidões", "excêntricos", etc., na verdade está-se desqualificando o papel subversivo intrínseco ao trabalho do artista. Ser escritor não tem nada de especial. Senta-se ao computador e escreve-se. O que me impele é a indignação. 
Mas a indignação é o que todo cidadão de bem deve carregar consigo. Há aqueles que, como médicos, transformam suas inquietações em ações de transformação da sociedade. Há aqueles que, como garis, encontrando uma soma de dinheiro na rua, procuram o dono para devolvê-lo. Isso se chama política. Cada um ocupa seu espaço no mundo. Entre os artistas, é a mesma coisa: há os conformados e os inconformados. Eu me alinho ao segundo time.

4. A relação entre autor e leitor pode ser descrita, segundo Gumbrecht, como a de uma "intimidade imaginada". ${ }^{1}$ Você se preocupa com o leitor durante a criação? Mantém-se atento à recepção dos seus livros?

LR: Mantenho-me, claro, atento à recepção dos meus livros, mas não me deixo envolver por ela. No momento em que um livro vai para as livrarias, ele deixa de ser meu. Não o defendo, ele tem que se defender sozinho. Se pensar em termos de leitores, fico felicíssimo quando algum deles - e são tão poucos - me aborda para dizer que se emocionou com uma cena ou outra, com um personagem ou outro, com uma história ou outra. Mas o meu caminho literário já está traçado. Não iria mudá-lo porque meus livros vendem pouco ou porque agradam somente a um pequeno grupo.

5. Eles eram muitos cavalos (2001) será relançado, em $\sigma^{a}$ edição revista, pela Record. Publicado na Itália, na França e em Portugal, recebeu os Prêmios Machado de Assis de Narrativa, da Fundaçâo Biblioteca Nacional, e APCA (Associação Paulista de Críticos de Arte), além de ter sido adaptado pela Companbia do Feijão no celebrado espetáculo "Mire Veja", de 2003. Qual o papel desse romance em sua bibliografia? Como ele, que retrata a vida frenética na capital paulista numa terça-feira do ano 2000, se relaciona com algumas de suas histórias, ambientadas em Cataguases, cidade pacata do interior de Minas?

LR: Este livro tem uma importância determinante na minha vida. Foi com a sua publicação que pude começar a pensar em abandonar o jornalismo para me dedicar exclusivamente à literatura. Ele deu visibilidade ao meu trabalho e angariou leitores. Mas, mais ainda, com ele encontrei o que buscava há vinte anos: uma forma adequada à minha

${ }^{1}$ GUMBRECHT, 1998. p. 299. 
temática. Eu diria que Eles eram muitos cavalos está mais próximo do projeto Inferno Provisório do que se possa imaginar. Em primeiro lugar, a experimentação formal presente em Eles eram muitos cavalos me apontou os caminhos que estou trilhando nos volumes do Inferno Provisório. E foi naquele livro que encontrei a minha dicção. Embora as histórias que compõem o Inferno Provisório tenham como base Cataguases, São Paulo e Rio de Janeiro são presenças constantes no horizonte dos personagens.

6. Na sua mudança da Boitempo para a Record, foram publicados, em 2005, os volumes inaugurais da série Inferno Provisório, que recuperam contos dos seus dois primeiros livros. A que se deve este retorno?

LR: A minha intenção, quando comecei a escrever, era dar um depoimento da minha época a partir da minha vivência como operário, filho de agricultores sem-terra. Para isso, me preparei durante quase vinte anos. Quando desenvolvi os "contos" que estão em Histórias de remorsos e rancores, de 1998, eu não havia resolvido ainda alguns impasses - por exemplo, como construir uma narrativa que desse conta da consolidação da classe operária brasileira, a partir da década de 1950 -, que não se resolveram nem mesmo quando publiquei os "contos" de (os sobreviventes), em 2000. Somente com a edição de Eles eram muitos cavalos, em 2001, entendi o caminho a ser seguido. Então, passei quatro anos reescrevendo as histórias presentes nesses dois primeiros livros e organizando o projeto Inferno Provisório, que terá cinco volumes. O primeiro, Mamma, son tanto felice (uma reapropriação de (os sobreviventes)), trata do êxodo rural: a desagregação de uma pequena comunidade de italianos desenraizados, moradores de Rodeiro, cujos jovens não vêem mais perspectiva naquela economia de subsistência, com falta de horizontes. O segundo volume, O mundo inimigo (uma reapropriação de Histórias de remorsos e rancores) flagra esse primeiro movimento em direção a uma cidade industrial, no caso, Cataguases, e o terrível embate entre os imaginários rural e urbano. O terceiro volume, Vista parcial da noite, mostra a formação da periferia de Cataguases - a compra de terrenos e a construção de casas próprias - e o movimento de migração rumo a São Paulo e ao Rio de Janeiro como possibilidade para se vencer a falta de perspectiva de ascensão social numa cidade pequena. O quarto volume, ainda não publicado, O livro das impossibilidades, discute os impasses da década de 1980, quando o país entra em profunda depressão econômica 
e se percebe, então, o engodo que as cidades grandes ofereciam. Finalmente, o quinto volume, ainda sem título, vai tratar da degeneração das cidades pequenas, que têm hoje todos os problemas das metrópoles - violência, favelização, desemprego, falta de solidariedade -, mas nenhum dos seus benefícios. Ou seja, trata-se de historiar o período negro da ditadura militar e a encruzilhada para onde ela conduziu o país. A linguagem também acompanha essa deterioração: começa extremamente influenciada pelo imaginário rural - seja na escolha do vocabulário, seja no ritmo da narrativa - e vai se "urbanizando" com a passagem do tempo. Na verdade, Eles eram muitos cavalos seria, assim, uma espécie de sexto volume da série...

7. A antologia Quando fui outro (2006) - que elenca poemas e textos em prosa de Fernando Pessoa, além de cartas dele para Ophélia-, por você organizada, revela o seu apreço pelo escritor. Em sua obra também são notados possiveis "diálogos". Por exemplo, no conto "O segredo", um professor, perseguido por sua paranóia, cria para si um julgamento - bem kafkiano - em que é condenado como um animal em praça pública. Outro autor que nela parece repercutir é Faulkner, referência sugerida pela fragmentação narrativa e pela confluência de vozes e de histórias, agregadas como mosaicos. Atenta-se, ainda, para a escolh a criteriosa das epígrafes dos livros, que citam a Bíblia, Carlos Drummond de Andrade, Jorge de Lima, Ferreira Gullar, Cecília Meireles. Qual o seu cânone pessoal? Como ele reverbera em sua obra?

LR: Penso que talvez possamos dividir os escritores em dois blocos: aqueles que contam uma história e aqueles que escrevem uma história. Eu sempre me identifiquei muito mais com os últimos, pois acho que, fundamentalmente, a literatura é apenas uma das várias maneiras de nos colocar em contato com o real, ou seja, ela não pode ter a pretensão de esgotar essas possibilidades. Nesse sentido, as minhas leituras confluem para autores que tenham como preocupação encontrar a forma ideal de explicitar um conteúdo. Podemos falar, então, de uma tradição do romance não convencional, que, se não começa, pelo menos passa necessariamente por Laurence Sterne e caminha com Anton Tchekov, com Marcel Proust, com William Faulkner, com Alain Robbe-Grillet, com Georges Pérec, entre outros - e, no Brasil, passa por Machado de Assis, por Dyonélio Machado, por Guimarães Rosa... Mas, no meu caso, acho impossível pensar em diálogos sem pensar na poesia - o que me obriga 
a falar em Charles Baudelaire, em Stephane Mallarmé, em Ezra Pound, em T.S.Eliot e em grandes nomes da poesia brasileira, citados na sua pergunta. Mas sempre e acima de tudo, a Bíblia, o maior repositório do conhecimento humano, de onde deriva grande parte do imaginário da literatura ocidental.

8. Muitas das antologias que você organiza conferem lugar às minorias. A mais recente delas, Entre nós (2007), versa sobre a questão da homossexualidade e abre a série "Lingua Franca", da Editora Lingua Geral, que se deterá em temas socialmente relevantes. Além disso, as suas histórias estão focadas na gente miúda e na vida desolada dos operários, mão-deobra explorada pelo sistema de produção. Você credita à literatura uma função social?

LR: Eu não escreveria se achasse que a literatura não tem nenhuma função social. Eu não tinha livros em casa e nem acesso a eles até os 12 anos, quando, por acaso, entrei na biblioteca do colégio para onde havia me transferido naquele ano e me deparei com um livro. Levei-o para casa e o li. Tive febre... A história se passava num lugar com temperaturas abaixo de zero, falava de gente com nomes impronunciáveis e relatava um episódio da Segunda Guerra Mundial, o massacre de judeus em Odessa. E eu, que nunca havia viajado para além de Ubá (a não ser para visitar três ou quatro vezes meu pai em Santos Dumont, onde passou o ano de 1967 internado num sanatório para tuberculosos), percebi que o mundo era mais amplo que Cataguases, que existiam pessoas em outros lugares que falavam outras línguas e que a humanidade podia ser crudelíssima - e que cabia a cada um de nós mudar a nossa vida... Foi esse livro, Bábi Iar, de Anatole Kusnetzov, que abriu meus olhos... Esta é a função social da literatura: mudar os homens. Como a sociedade é um conglomerado de homens, obviamente a literatura pode transformá-la... Não é à toa que, quanto menos um país investe em educação, mais propenso está à corrupção, à ditadura, à mediocridade...

9. No prefácio do livro Ascânio Lopes, todos os possíveis caminhos, você afirma que "'O revoltado' exacerba o olhar de Ascânio, que antecipa, de maneira surpreendente, um filão até hoje pouquissimo explorado na literatura brasileira: a reflexão sobre a vida operária [...]." (2005, p.27) Ao longo da sua obra, percebe-se que certo cenário cataguasense é sistematicamente reiterado. Esse recorte espacial é determinante tanto para 
a contextualização de um universo operário como para a caracterização dos personagens. Com a "pentalogia" Inferno Provisório, hoje no terceiro volume, você pretende investigar a sociedade sob a ótica da passagem dos preceitos agrários para os pós-industriais. O seu projeto literário foi planejado com o propósito de amainar esta lacuna?

LR: Sim. Foi a partir dessa constatação que me senti tentado a dar uma contribuição. É interessante porque a literatura brasileira, com raras exceções, sempre foi produzida por autores provenientes da classe média alta ou da aristocracia ou da burguesia. Então, temos bem representados os tipos urbanos - burocratas, agregados, jornalistas, médicos, etc., e os seus contrários, os malandros e, depois, os marginais e, agora, os bandidos - e os tipos rurais - os fazendeiros e os camponeses. Mas os operários urbanos são invisíveis. Tirando aqueles autores que, ancorados no proselitismo político, retrataram militantes, o operário urbano aparece no romance Os Corumbás, de Amando Fontes, em toda a obra de Roniwalter Jatobá e no horizonte de Fernando Bonassi.... E olha que, pelo menos a partir da década de 1950, somos um país essencialmente industrial. Por que isso ocorre? Porque, no Brasil, apesar de parecer o contrário, a mobilidade social é mínima...

10. No livro mencionado na pergunta anterior, você declara: "Ascânio sempre me fascinou. Filho do proletariado, com irmão e irmã trabalhando na indústria têxtil-eu mesmo mão-de-obra desqualificada numa fábrica de algodão hidrófilo-, extasiava-me a sensibilidade do poeta para as coisas da sua cidade, que me eram, e são ainda hoje, e cada vez mais, caras, como seu olhar solidário para com o trabalhador." (2005, p.16-17) Através da sua obra, revelam-se uma vivência apurada do espaço cataguasense e de um imaginário popular, como exemplificam os contos "A decisão" e "Carta a uma jovem senhora", que marcam a idealização da vida no Rio de Janeiro, topos de um futuro sem agruras contraposto a Cataguases, cidade referenciada como um "buraco" em "A solução" $e$ "Amigos". Qual o papel de Cataguases no seu imaginário?

LR: Cataguases é uma cidade industrial desde o começo do século XX. Isso fez com que, diferentemente da maior parte das outras cidades do Brasil, lá houvesse uma estratificação bastante clara entre as classes sociais: a burguesia, a classe média prestadora de serviços, os proletários e o lúmpen. Portanto, as contradições eram mais evidentes - diferentemente, por exemplo, do restante da Zona da Mata mineira, formada por núcleos 
urbanos decadentes e por uma sociedade em que as relações de classe eram difusas e as idéias, impermeáveis. Eu tive o privilégio de transitar entre esses dois mundos, pois morava em Cataguases, mas passava minhas férias com a família da minha mãe entre Rodeiro e Ubá. Acompanhei bem de perto o processo de êxodo rural e a exploração da mão-de-obra não qualificada que vinha da roça. Depois tive contato direto com o crescimento do interesse por buscar nova vida em São Paulo e no Rio de Janeiro - na maioria dos casos, uma infrutífera e desastrosa compensação para os malogros da cidade pequena, sem perspectiva. Evidentemente, a minha Cataguases é ficção. As ruas, praças e pessoas que cito existem para mim, embora calcadas no espaço real. Talvez, nem sejam espaços reconhecíveis...

11. O seu trabalho Os ases de Cataguases (2002), escrito na década de 1980, busca entender o "fenômeno Cataguases" pertinente à revista Verde. ${ }^{2}$ A revista, que repercutiu nacionalmente, influenciou movimentos culturais das geraçôes seguintes. Em que medida você se identifica com os "verdes" ou deles se distancia?

LR: Eu nasci em Cataguases - embora minha relação com a cidade seja apenas e tão somente essa, já que minhas raízes (nem sei se posso falar em raízes) não estejam lá (sempre me pergunto: afinal, onde estão?). Só fui descobrir que Cataguases era uma cidade importante do ponto de vista cultural (literatura, cinema, arquitetura) depois que saí de lá... Foi só na década de 1980, já morando em Juiz de Fora, que me dei conta do espaço urbano onde morava. E aí fui pesquisar. Sempre se falava, e ainda se fala que Cataguases é um "fenômeno inexplicável". Ora, nunca engoli essa história. Daí nasceu esse livro, que mostra, acho que de maneira bastante razoável, a ligação entre a inversão de capitais oriundos da economia cafeeira na criação de um parque industrial e o financiamento da cultura na cidade. Essa equação se consolidou e perdura até hoje. Mas não há, da minha parte, nem identificação, nem distanciamento em relação aos "verdes". Há a consciência de que sou um de seus vários desdobramentos.

\footnotetext{
${ }^{2}$ Revista literária - publicada entre setembro de 1927 e maio de 1929, totalizando seis números - antenada às diretrizes estéticas do Modernismo paulista, organizada em Cataguases por Ascânio Lopes, Enrique de Resende, Francisco Inácio Peixoto, Guilhermino César, Rosário Fusco, entre outros.
} 
Por exemplo: a preocupação com a fixação do operário como personagem inerente à cidade já existe, na década de 1920, em Francisco Inácio Peixoto (excelente contista) e em Ascânio Lopes (bom poeta), ainda que de maneira incipiente, errática e transitória. A experimentação formal como parte integrante da pesquisa literária é subsidiária da poesia de vanguarda desenvolvida pelo grupo liderado por Joaquim Branco, na década de 1960, por sua vez descendente direto das inquietações dos "verdes". Portanto, existe um diálogo, digamos assim, geracional.

12. As suas histórias condicionam um horizonte de penúria, não só financeira, como afetiva e emocional, retratando a vida segundo sua faceta mais precária, degradada e desesperançada. Por que, como anuncia a epigrafe de Carlos Drummond de Andrade, "toda história é remorso"?

LR: A imigração é um fenômeno econômico: deixa-se o lugar de origem para buscar melhores condições de vida. Ou seja, não é uma opção, é falta de opção. Quando se migra, mais que deixar para trás hábitos, costumes, sotaques e amigos, abandonam-se os mortos no cemitério, pois não é possível carregar os ossos. Os mortos são a história: quando se migra, perde-se o contato com a mais profunda subjetividade, aquilo que faz com que você seja um, e não outro. O Brasil conheceu várias vezes esse fenômeno: foi assim quando os portugueses aqui chegaram, forçando os índios a se embrenharem cada vez mais para dentro das florestas; foi assim quando milhões de negros foram escravizados na África e trazidos para trabalhar à força; foi assim quando a miséria empurrou milhões de europeus e japoneses para a lavoura no Sul-Sudeste; foi assim quando, necessitando de mão-de-obra barata, a burguesia - que é a antiga aristocracia - de São Paulo e do Rio de Janeiro importou milhões de braços nordestinos e mineiros para povoarem as periferias em troca de salários mínimos. Essa é a nossa história, uma história de violência, de imposição do poder à força, de perpetuação de sobrenomes...

13. Há alguns anos, ensaiou-se uma querela a respeito dos rumos da literatura brasileira contemporânea. Nessa ocasião, foram delimitados dois grupos: um encabeçado por Bernardo Carvalho e Milton Hatoum e outro por representantes da "geração 90", rótulo que alude a você, Nelson de Oliveira, Marçal Aquino, Fernando Bonassi, Marcelo Mirisola, Marcelino Freire, entre outros autores. Um dos pontos mais significativos dessa segmentação incidia sobre maneiras diferentes de se matizar a percepção 
literária da realidade. Outro ponto polêmico é o que contornava as estratégias que ativam a vida literária, com destaque para a batalba pelo espaço mercadológico. Como você avalia tais rumos?

LR: A crítica tem necessidade de categorizar por uma questão de método. Eu não sei se existem esses dois grupos, se eles são antagônicos ou complementares. Todos esses autores citados e dezenas de outros não citados estão fazendo a literatura brasileira contemporânea. Não sei se bem ou mal, se melhor ou pior do que já se fez, mas, com certeza, é o que temos. Os vários caminhos que se colocam hoje - ou porque as editoras passaram a se interessar pelos autores nacionais, ou porque há maior facilidade hoje para se publicar - abrem a possibilidade para tentarmos compreender a complexidade da nossa sociedade. Acho que é um momento extramente frutífero - o que advirá daí, no entanto, não sei...

\section{Referências Bibliográficas}

GUMBRECHT, Hans Ulrich. Modernização dos sentidos. Trad. Lawrence Flores Pereira. São Paulo: Ed. 34, 1998. 320 p.

LOPES, Ascânio. Ascânio Lopes, todos os possiveis caminhos. Org., prefácio e notas: Luiz Ruffato. Cataguases: Instituto Francisca de Souza Peixoto, 2005. 201p.

RUFFATO, Luiz. Os ases de Cataguases: uma história dos primórdios do Modernismo. Cataguases: Instituto Francisca de Souza Peixoto, 2002. 125 p. 